\title{
Liver Cirrhosis and Rhino-Orbital Mucormycosis, a Possible But Rare Association: Description of a Clinical Case and Literature Review
}

\author{
Adriano M Pellicelli, Cecilia D’Ambrosio, Roberto Villani, Giuseppe Cerasari, Pasquale Ialongo, Andrea Cortese, Lucia \\ Rosalba Grillo and Fabrizio Soccorsi \\ Liver Unit San Camillo Forlanini Hospital Rome Italy; Pathology,Histology and Diagnostic Cytology San Camillo Forlanini Hospital Rome \\ Italy; Department of Radiology San Camillo Forlanini Hospital Rome Italy
}

\begin{abstract}
Only few cases of rhino-orbital mucormycosis in patients with liver cirrhosis are described in the literature and most of these patients showed an associated diabetes mellitus. We describe a case of rhino-orbital mucormycosis in a patient with liver cirrhosis without other risk factors.
\end{abstract}

Key-Words: Liver cirrhosis, rhino-orbital mucormycosis, immunocompromised patients, mucor, surgical treatment.

Rhino-orbital mucormycosis has emerged in the last years as an increasingly important life-threatening infection. Since 1885 more than 929 cases were described in the literature [1]. In the cases reported, diabetes mellitus was the most common underlying condition but other predisposing conditions as haematological malignancy, bone marrow transplantation, solid organ transplantation, injection drug users, recipients of deferoxamine therapy and solid tumors were described in the literature [1]. In the case herein reported, we describe a case of rhino-orbital mucormycosis in a patient with liver cirrhosis due to Hepatitis $C$ virus. At the present only other 9 cases of rhinoorbital mucormycosis in cirrhotic patients are reported in the literature. Liver cirrhosis seems to be a predisposing factor for rhino-orbital mucormycosis. We analyze the pathogenetic mechanism that could be at the basis of this fungal disease in cirrhotic patients and we review the literature.

\section{Case Report}

A 63 year old woman with a know history of Child-Pugh B class liver cirrhosis secondary to hepatitis $C$ virus infection was admitted to our hospital for periorbital pain and swelling of two weeks of duration. At the time of the admission the patient was alert and oriented, her vital signs included a temperature of $36.9 \mathrm{C}^{\circ}$, an heart rate of $90 \mathrm{bpm}$, and an arterial blood pressure of 135/85 mmHg. On physical examination, considerable hepato-splenomegaly and the presence of ascitic fluid was disclosed. Furthermore, a proptosis associated to red and swollen right eyes was present. There was also a pronounced right maxillary tenderness. One month prior, she was admitted to another hospital with headache and it was diagnosed a paranasal sinusitis. Results of laboratory examinations included white blood cell count of 2,000 cells/ $\mathrm{mm}^{3}$ with $45 \%$ of neutrophils, hemoglobin level of $9.2 \mathrm{~g} / \mathrm{dL}$, and platelet count of $60,000 / \mathrm{mm}^{3}$, erythrocyte sedimentation time of $100 \mathrm{~mm}$, reactive $C$ protein of $6 \mathrm{mg} / 100 \mathrm{~mL}$ and normal plasmatic glucose level $(85 \mathrm{mg} / 100 \mathrm{~mL})$. Urgent computed

Received on 8 May 2009; revised 7 July 2009.

Address for correspondence: Dr. Adriano M Pellicelli Via Terni 97 00182. Email: HUadriano.pellicelli@tiscali.itUH apellicelli@scamilloforlanini.rm.it. Fax +39658704343 tel number +39658704369 .

The Brazilian Journal of Infectious Diseases

2009;13(4):314-316 (C) 2009 by The Brazilian Journal of Infectious Diseases and Contexto Publishing. All rights reserved. tomography demonstrated right density-shadow of the soft tissue in the right maxillary sinus, ethmoid sinus, and sphenoid sinus (Figure $1 \mathrm{~A}$ ). Biopsy of right maxillary sinus was performed and biopsy specimen revealed non-septate hyphae branching at right angles consistent with Mucor species (Figure 1 B-C). The patient underwent right orbital exerentation, right ethmoidectomy, maxillectomy and partial sphenoidectomy (Figure 2 A-B). She began receiving amphotericin $\mathrm{B}$ at a beginning dosage of $0.5 \mathrm{mg} / \mathrm{Kg} / \mathrm{day}$ ev and subsequently at a dose of $1 \mathrm{mg} / \mathrm{Kg} /$ day. Her creatinine level increased to $2.5 \mathrm{mg} / \mathrm{mL}$ and amphotericin B treatment was stopped. The patient, after few days, had clinical improvement and recovery of renal function. A treatment with liposomal amphotericin B $5 \mathrm{mg} / \mathrm{Kg} /$ die was subsequently initiated. After one month of treatment, she was discharged from hospital. At eight months of follow up no evidence of recurrent infection was noted.

\section{Discussion}

Several infectious diseases are common among patients affected by liver cirrhosis [2]. Rhino-orbital mucormycosis is rare in cirrhotic patients. Risk factors that can contribute to development of this severe fungal disease are: diabetes mellitus, use of systemic steroid, immunodeficiency, neutropenia, haematological malignancies, bone marrow and solid organ transplantation. In the literature, only nine clinical cases of rhino-orbital mucormycosis in cirrhotic patients are described (Table 1). In the 10 cases reported in this article, diabetes was present in six patients $(60 \%)$, while complications related to liver cirrhosis, as hepatocellular carcinoma, spontaneous bacterial peritonitis and portosystemyc encephalopathy were present in 5 patients. A strict association between diabetes mellitus and liver cirrhosis exists, in particular an increased risk of developing diabetes mellitus is present in patients with liver cirrhosis due to hepatitis $\mathrm{C}$ and alcoholic liver disease while the risk is reduced in liver cirrhosis due to cholestatic liver disease [7]. Development of mucormycosis in cirrhotic patients with associated diabetes mellitus may reflect compromised immunity of the patient from diabetes mellitus more than liver disease. Diabetes mellitus represents the strongest risk factor to develop rhinocerebral mucormycosis. Chronic 
Figure 1. (A) Contrast enhanced computed tomography. Extensive soft tissue density was noted in right maxillary and sphenoid sinuses. The process shows an extension to into the ipsilateral ethmoidal air cells and to the maxillary bone. (B) Biopsy speciment of the maxillary sinus revealed non septate hyphae brancing at right angles a finding consistent with Mucor species (Periodic acid Shiff stain x 250). (C) Biopsy speciment showing mucormycosis hyphae (haematoxylin and eosin stain original magnification, $\mathrm{x} 400$ ).
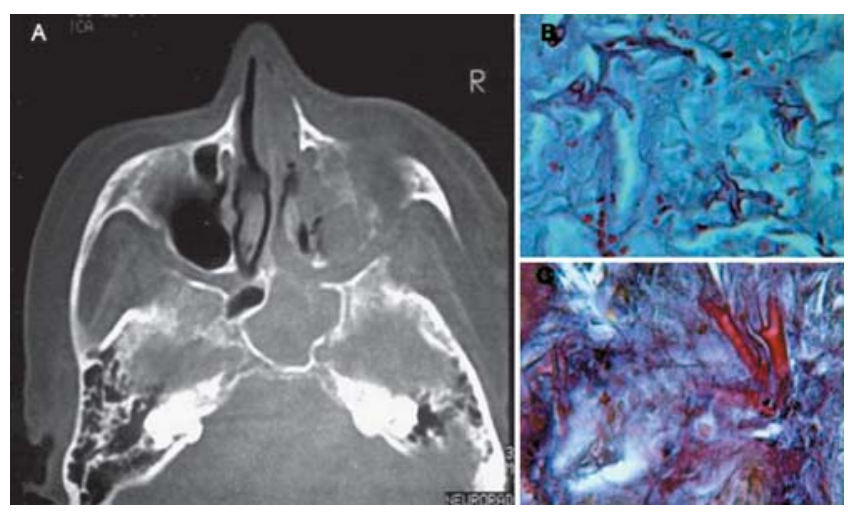

Figure 2. (A) Post surgical contrast enhanced computed tomography. Extensive surgical procedures with total enucleation of right eyeball and (B) a pansinusectomy was performed.

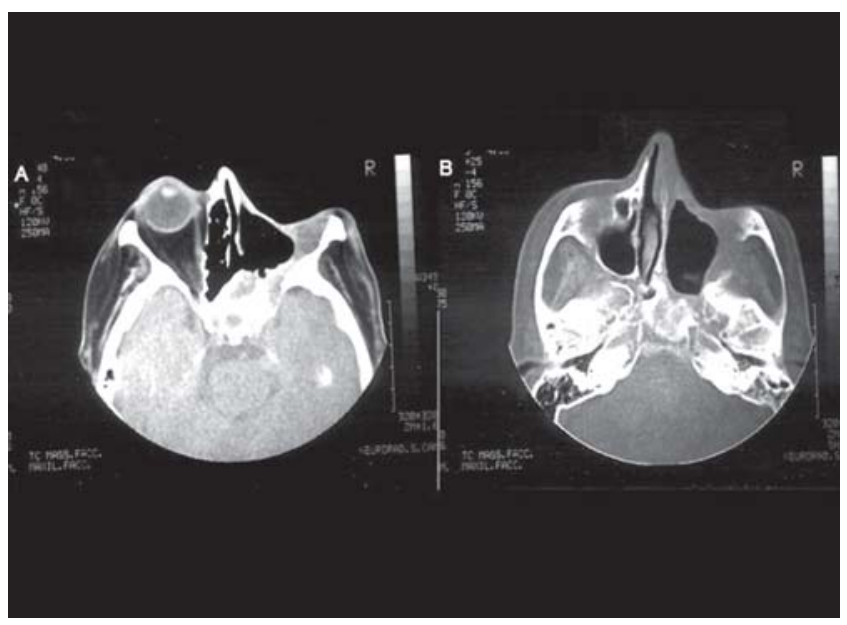

Table 1. In the table are reported all the cases of rhino-orbital mucormycosis reported in the literature.

\begin{tabular}{|c|c|c|c|c|c|c|c|c|c|}
\hline Pts $n^{\circ}$ & Ref. & $\begin{array}{c}\text { Age/ } \\
\text { gender }\end{array}$ & $\begin{array}{c}\text { Child } \\
\text { Pugh class }\end{array}$ & Etiology & Cirrhosis & $\begin{array}{l}\text { Comorbidity } \\
\text { complication }\end{array}$ & CT & Treatment & Follow up \\
\hline 1 & [3] & 39/M & B & $\mathrm{HCV}$ & none & $\begin{array}{c}\text { LC } \\
\text { DM }\end{array}$ & $\begin{array}{l}\text { Maxillary, ethmoid } \\
\text { and sphenoid sinus, } \\
\text { cerebral }\end{array}$ & Surgery/AmB & Died \\
\hline 2 & [3] & 57/M & $\mathrm{C}$ & $\mathrm{HCV}$ & $\begin{array}{l}\text { PSE, SBP, } \\
\text { HCC }\end{array}$ & LC & Not done & $\mathrm{AmB}$ & Died \\
\hline 3 & [3] & 55/M & $\mathrm{C}$ & $\mathrm{HBV}$ & $\begin{array}{l}\text { PSE, SBP, } \\
\text { HRS HCC }\end{array}$ & LC & $\begin{array}{l}\text { Maxillary and } \\
\text { ethmoid sinus }\end{array}$ & None & Died \\
\hline 4 & [3] & $15 / F$ & $\mathrm{C}$ & $\begin{array}{l}\text { Autoimm } \\
\text { hepatitis }\end{array}$ & PSE, SBP & $\begin{array}{c}\text { LC, } \\
\text { DM, } \\
\text { steroid therapy }\end{array}$ & Maxillary sinus & None & Died \\
\hline 5 & [3] & 53/M & $\mathrm{C}$ & $\mathrm{HCV}$ & none & $\begin{array}{l}\text { LC, } \\
\text { DM }\end{array}$ & $\begin{array}{l}\text { Maxillary, ethmoid } \\
\text { and sphenoid } \\
\text { sinuses, orbit, } \\
\text { cerebral }\end{array}$ & $\begin{array}{l}\text { Surgery (Orbit } \\
\text { enucleation and } \\
\text { endoscopic } \\
\text { debridement of } \\
\text { sinuses) /AmB }\end{array}$ & Died \\
\hline 6 & [3] & 35/M & $\mathrm{C}$ & $\mathrm{HCV}$ & SBP, HRS & $\begin{array}{l}\text { LC, } \\
\text { DM }\end{array}$ & $\begin{array}{l}\text { Maxillary ethmoid } \\
\text { and sphenoid sinus, } \\
\text { orbit }\end{array}$ & $\mathrm{AmB}$ & Died \\
\hline 7 & [4] & $44 / F$ & B & $\begin{array}{l}\text { Not } \\
\text { reported }\end{array}$ & $\begin{array}{l}\text { Not } \\
\text { reported }\end{array}$ & LC & Ethmoid sinus, orbit & None & Died \\
\hline 8 & [5] & $58 / F$ & $\mathrm{C}$ & $\begin{array}{l}\text { Not } \\
\text { reported }\end{array}$ & None & $\begin{array}{c}\text { LC, } \\
\text { DM, RI }\end{array}$ & $\begin{array}{l}\text { Paranasal sinuses, } \\
\text { orbit, cerebral }\end{array}$ & $\begin{array}{l}\text { Liposomial } \\
\text { AmB }\end{array}$ & Died \\
\hline 9 & [6] & 53/M & B & $\mathrm{HCV}$ & $\mathrm{HCC}$ & $\begin{array}{l}\mathrm{LC} \\
\mathrm{DM}\end{array}$ & Not done & None & Died \\
\hline 10 & $\begin{array}{l}\text { Case } \\
\text { reported }\end{array}$ & $63 / F$ & B & $\mathrm{HCV}$ & none & LC & $\begin{array}{l}\text { Maxillary, ethmoid, } \\
\text { sphenoid sinuses, } \\
\text { orbitand }\end{array}$ & $\begin{array}{l}\text { Surgery/AmB } \\
\text { Liposomial AmB }\end{array}$ & Alive \\
\hline
\end{tabular}

Pts=patients Ref= referencesM=male, $\mathrm{F}=$ female, $\mathrm{C}=$ hepatitis $\mathrm{C}$ virus, $\mathrm{B}=$ hepatitis $\mathrm{B}$ virus, $\mathrm{PSE}=$ portosystemyc encephalopathy, $\mathrm{SBP}=$ spontaneous bacterial peritonitis, HRS=hepatorenal syndrome, LC=Liver cirrhosis, RI=Renal insufficiency, HCC=heatocellular carcinoma, DM=diabetes mellitus, $\mathrm{HTN}=$ arterial hypertension, $\mathrm{CT}=$ Computed tomography, $\mathrm{AmB}=$ amphotericin $\mathrm{B}$. 
hyperglycaemia impairs host defense mechanism such as cell mediated immunity, polymorphonuclear leukocyte function and antibody formation, in particular reduced leukocyte function predispose to fungal infection.

Rhino-orbital mucormycosis seems to affect patients with end stage liver disease, in fact all 10 patients herein reported, presented a functional Child-Pugh class B and C as observed in decompensated liver disease. In 4 cases out of 10, liver cirrhosis was not associated with other comorbidities. Furthermore in two of these four patients complications related to liver cirrhosis as hepatocellular carcinoma, portosystemic encephalopathy and spontaneous bacterial peritonitis, were present. Patients with decompensated liver cirrhosis have an increased susceptibility to develop opportunistic infections as rhinocerebral mucormycosis for an alteration of neutrophils chemotaxis and phagocytosis [8,9]. Neutrophil metabolic activity diminishes together with the intensification of liver failure and the metabolic potential of phagocytizing neutrophils is significantly lower in liver cirrhosis patients.

Neutropenia is frequently present in end stage liver disease as expression of hypersplenism and of an accelerated neutrophils apoptosis. In a study of Kusaba et al. it was demonstrated that, in cirrhotic patients, exist an altered neutrophil kinetic and that an accelerated apoptosis is at the basis of neutropenia [10]. All these alterations can predispose to a more frequent bacterial and fungal infections in these patients. Despite aggressive surgical and medical treatment the prognosis of rhino-orbital mucormycosis is poor and the presence of brain abscesses further reduce the survival [11]. The main stays of therapy are surgical intervention and treatment with high dose of amphotericin B. In advanced liver disease, deranged coagulation and thrombocytopenia make surgical intervention difficult to realize. The reported mortality rates in patients with cirrhosis undergoing various non transplant surgical interventions range from 8.3 to $25 \%$ and this wide range of mortality is related to severity of liver disease. Elective surgery is tolerated in Child-Pugh A and possible in Child-Pugh B cirrhosis while child-Pugh $\mathrm{C}$ is an absolute contraindication to surgical procedures [12]. In our case, a surgical intervention with removal of all involved tissues was performed with an important local control of fungal infection and without post operative complications. Furthermore, medical treatment with liposomal amphotericin B was started. Liposomal amphotericin B has the advantage to be utilized to an higher concentration and with a reduced incidence and severity of amphotericin B nephrotoxicity. In two studies, a small number of patients with mucormycosis infection were treated with either liposomal amphotericin B or amphotericin B lipid complex with minor collateral effects and a response rate of 75\% [13-14] respect to conventional amphotericin B. In the clinical cases herein reported, only other two patients with associated diabetes mellitus were treated with a combined surgical and medical therapy. In one of these patients, only a palliative surgical treatment was allowed due to high surgical risk and in the other patient an extension of mucormycosis to the cerebral tissue was present. In our case, an adequate surgical and medical treatment was allowed due to less advanced liver disease and to an high compliance of the patient to liposomal amphotericin B treatment.

In conclusion, this paper describes the clinical presentation and outcome of one case of rhino-orbital mucormycosis in a patient in which the only risk factor was represented by liver cirrhosis. Advanced liver cirrhosis could predispose to rhinoorbital mucormycosis through an alterated function of white blood cells and in particular an alteration of neutrophils chemotaxis and phagocytosis. Despite aggressive surgical and medical treatment, the prognosis of rhino-orbital mucormycosis is poor. In selected patients, in which, a radical surgical approach and a good compliance to medical treatment with liposomal amphotericin B is achievable, the outcome was better respect to other patient with a more aggressive liver disease and with other comorbidity factors as diabetes mellitus and renal insufficiency.

\section{References}

1. Roden M.M, Zaoutis T.E, Buchanan W.L., Knudsen TA, Sarkisova TA, Schaufele RL et al. Epidemiology and outcome fo zygomycosis: a review of 929 reported cases: Clin Infect Dis. 2005;41: 634-653.

2. El Serag H.B, Anand B., Richardson P., Rabeneck L. Association between hepatitis $\mathrm{C}$ infection and other infectious disease: a case for targeted screening?. Am J Gastroenterol. 2003; 98: 167-174.

3. Abbas Z., Jafri W., Rasool S., Abid S, Hameed I. Mucormycosis in patients with complicated cirrhosis. Singapore Med J. 2007; 48:69-73.

4. Hofman P., Gari-Toussaint M., De Bievre C., Michiels JF, d'Horpock FA, Loubière R. Rhino-orbito-cerebral mucormycosis caused by Rhizopus oryzae. A typical case in a cirrhotic patients: Ann Pathol 1993; 13:180-183

5. Georgopoulou S., Kounougeri E, Katsenos C, Rizos M, Michalopoulos A. Rhinocerebral mucormycosis in a patient with cirrhosis and chronic renal failure. Hepatogastroenterology. 2003; 50:843-845.

6. Kikuchi H., Kinoshita Y:, Arima K, Doh-ura K, Hisatomi Y, Hashimoto T, Sakai H, Nawata H, Iwaki T. An autopsy case of rhino-orbito-cerebral mucormycosis associated with multiple cranial nerve palsy and subsequent subarachnoid hemorrhage. Rinsko Shinkeigaku. 1998; 38:252-255

7. Zein NN., Abdulkarim AS., Wiesner RH, Egan KS, Persing DH. Prevalence of diabetes mellitus in patients with end stage liver cirrhosis due to hepatitis $\mathrm{C}$, alcohol or cholestatic disease. J.Hepatol 2000; 32:209-217

8. Fiuza C., Salcedo M., Clemente G, Tellado JM. In vivo neutrophil dysfunction in cirrhotic patients with advanced liver disease. J Infect Dis. 2000;182:526-533

9. Campbell A.C., Dronfield M.W, Toghill P.J, Reeves WG. Neutrophil function in chronic liver disease. Clin Exp.Immunol. 1981; 45:81-89.

10. Kusaba N, Kumashiro R., Ogata H, Sata M, Tanikawa K. In vitro study of neutrophil apoptosis in liver cirrhosis. Intern. Med.1998;37:11-17

11. Kameh DS, Gonzalez OR, Pearl GS, Walsh AF, Gambon T, Kropp TM. Fatal rhino-orbital-cerebral zygomycosis. South Med J. 1997; 90:1133-5

12. Millwala F., Nguyen GC., Thuluvath PJ. Outcomes of patients with cirrhosis undergoing non hepatic surgery: risk assessment and managment. World J Gastroenterol. 2007; 14:4056-4063

13. Walsh T., Hiemenz J.W., Seibel N, Perfect JR, Horwith G, Lee L, et al. Amphotericin B lipid complex for invasive fungal infections: analysis of safety and efficacy in 556 cases. Clin Infect Dis. 1998;26:1383-1396

14. Ng T.T.C, Dennings D.W. Liposomal amphotericin B (Ambisome) therapy in invasive fungal infections. Arch Intern Med. 1995;155: 1093-1098. 